\title{
Uma Crítica ao Ofício de Professor e uma Proposta Construtivista para Tempos de COVID-19: a estratégia didática multissensorial adaptada ao ensino remoto emergencial
}

\author{
A Critique of the Teaching Profession and a Constructivist Proposal for COVID-19 Times: \\ the multisensory didactic strategy adapted to emergency remote teaching
}

\author{
Guilherme Lima Moura
}

Universidade Federal de Pernambuco, Pernambuco, Brasil.

\begin{tabular}{|c|c|}
\hline I N F O A R T I GO & RESUMO \\
\hline $\begin{array}{l}\text { Palavras-chave: } \\
\text { Ensino Remoto } \\
\text { Emergencial, } \\
\text { Ensino à Distância, } \\
\text { Pandemia da COVID-19, } \\
\text { Ensino Superior no Brasil, } \\
\text { Estratégia Didática } \\
\text { Multissensorial. }\end{array}$ & $\begin{array}{l}\text { Este artigo, tendo como mote o Ensino Remoto Emergencial (ERE) na } \\
\text { pandemia de COVID-19, especificamente na educação superior brasileira, } \\
\text { discute criticamente o papel de professores, professoras, alunas e alunos no } \\
\text { processo de ensino-aprendizagem. Ao mesmo tempo em que faz a crítica ao } \\
\text { nosso ofício de professores e professoras, retorna o olhar às nossas } \\
\text { circunstâncias práticas, para dizer que é possível criarmos estratégias } \\
\text { didáticas que favoreçam a aprendizagem dos alunos e das alunas, mesmo nas } \\
\text { condições limitantes inerentes ao ERE. Para isso, propõe a adoção do que } \\
\text { denominou Estratégia Didática Multissensorial, com base na sua aplicação ao } \\
\text { ERE, por três semestres letivos, em sete turmas, de três cursos, de dois camp } \\
\text { da UFPE. Por fim, defende que esta proposta metodológica de ensino - } \\
\text { classificada como uma estratégia didática construtivista - pode ser utilizada } \\
\text { através das plataformas Zoom }{ }^{\circledR} \text { e Google Classroom }{ }^{\circledR} \text {, com ganhos } \\
\text { significativos em relação aos obstáculos e desafios próprios do ERE. }\end{array}$ \\
\hline ARTICLE INFO & A B S T R ACT \\
\hline $\begin{array}{l}\text { Keywords: } \\
\text { Emergency Remote } \\
\text { Learning, } \\
\text { Distance learning, } \\
\text { COVID-19 Pandemic, } \\
\text { Higher Education in } \\
\text { Brazil, } \\
\text { Multisensory Didactic } \\
\text { Strategy. }\end{array}$ & $\begin{array}{l}\text { This paper, considering the Emergency Remote Teaching (ERT) in the } \\
\text { COVID-19 pandemic, in Brazilian higher education, discusses the role of } \\
\text { teachers and students in the teaching-learning process. At the same time that } \\
\text { it criticizes our profession as teachers, the text returns to our practical } \\
\text { circumstances, to say that it is possible to create didactic strategies that favor } \\
\text { the learning of students, even in the limiting conditions inherent to the ERT } \\
\text { For this, the article proposes the adoption of the Multisensory Didactic } \\
\text { Strategy, based on its application to the ERT for three academic semesters, in } \\
\text { seven classes of three courses at two UFPE campuses. Finally, it defends that } \\
\text { this methodological teaching proposal - classified as a (reasonably) } \\
\text { constructivist didactic strategy - can be used through the Zoom }{ }^{\circledR} \text { and Google } \\
\text { Classroom }{ }^{\circledR} \text { platforms, with significant gains over the obstacles and } \\
\text { challenges inherent to the ERT. }\end{array}$ \\
\hline
\end{tabular}




\section{Correspondência para autores:}

glmoura@gmail.com (Moura, G.L.) (ORCID: 0000-0003-2729-5286)

\section{Introdução}

Se o leitor e a leitora deste artigo forem típicos pesquisadores e pesquisadoras brasileiros (SCHULZ, 2021), é provável que sejam também professores e professoras de Instituições de Ensino Superior (SENADO FEDERAL, 2021). E se isso for verdade, é ainda mais certo que participam (ou participaram em algum momento), desde o início da Pandemia da COVID-19, e nem sempre de bom grado, da massificação do uso de ambientes virtuais de ensino remoto, ocorrida não apenas nas graduações e pós-graduações do país, mas em todo o sistema educacional brasileiro (RODRIGUES, 2021).

Não é de se espantar, portanto, que esse assunto esteja continuamente em evidência. E não estamos nos referindo tão somente à pandemia em si - com todo o seu efeito devastador ainda em curso. É também grave e urgente nos perguntarmos: qual o sentido do ensino neste contexto de distanciamento social?

Em verdade, a questão se desdobra para além deste momento. De tal modo que estamos, professores e professoras, inevitavelmente impactados pela possibilidade da permanência do assim chamado Ensino Remoto Emergencial (ERE), mesmo em um futuro de convivência social "normal". Dito de outra forma, mesmo quando for possível nos reunirmos em grupo, com uma satisfatória segurança sanitária em uma sala de aula tradicional, terão ficado para trás estas tais atividades de ensino remotas? Ou elas vieram para ficar (assim como o vírus que nos aflige)?

Estamos falando, portanto, não apenas sobre o uso de metodologias de ensino-aprendizagem mediadas ou não pelas Tecnologias de Informação e Comunicação (TICs). Não se trata tão-só de questionarmos a validade das interações assíncronas em substituição (ou em suplemento) às síncronas; ou de compararmos aulas presenciais com aulas à distância - embora estes também sejam aspectos graves desta discussão, frequentemente abordados quando analisamos o Ensino à Distância (EaD) (MOURA, 2008). A questão que subjaz à confusão surgida com este nosso mergulho repentino nas "aulas virtuais" diz respeito, efetivamente, ao sentido do nosso ofício de professor e de professora.

É assim que este texto, tendo como mote o ERE em meio à pandemia de COVID-19, especificamente na educação superior brasileira, discute criticamente o papel de professores, professoras, alunas e alunos no processo de ensino-aprendizagem. Ao mesmo tempo em que faz a crítica ao nosso ofício de professores e professoras, retorna o olhar às nossas circunstâncias práticas, para dizer que é possível criarmos estratégias didáticas que favoreçam a aprendizagem dos alunos e das alunas, mesmo nas condições limitantes inerentes ao ERE. Para isso, propõe a adoção do que denominou Estratégia Didática Multissensorial, com base na sua aplicação ao ERE, por três semestres letivos, em sete turmas, de três cursos, de dois campi da UFPE. Por fim, defende que esta proposta metodológica de ensino - classificada como uma estratégia didática construtivista - pode ser utilizada através das plataformas Zoom® e Google Classroom®, com ganhos significativos em relação aos obstáculos e desafios próprios do ERE.

Para atingir esse propósito, então, o artigo segue adiante caracterizando brevemente o ERE, no que parece ser uma tentativa contraditória de diferenciá-lo e assemelhá-lo com o EaD, porque é justo nestas semelhanças que reside a essência das nossas dificuldades (seção 2). Em seguida, ele aponta algumas das principais dificuldades surgidas com a forma como fomos "arremessados" no ERE, em função do nosso 
contexto emergencial. Sim, parte das nossas queixas procedem realmente deste processo atabalhoado que torna o ERE ainda mais problemático (seção 3). Na sequência, apresenta uma brevíssima definição do que está sendo chamado aqui de "construtivista", obviamente sem qualquer intenção de aprofundar o tema, mas para que se tenha clareza dos aspectos evocados no texto (seção 4). Feito isto, são apresentadas as bases da Estratégia Didática Multissensorial e seu uso adaptado a situação real de ERE no ensino superior (seção 5). Por fim, são apresentadas algumas considerações finais (seção 6).

\section{EaD versus ERE: o nosso drama está nas diferenças ou nas semelhanças?}

Importante esclarecer de partida que existem diferenças importantes entre o EaD e o ERE (ROCHA, 2021), ao qual a imensa maioria dos estudantes brasileiros têm se submetido nestes dois últimos anos.

"Em tempos de pandemia, o que a maioria das instituições educacionais que estão mantendo elou retomando suas atividades está fazendo é adaptar, provisoriamente, o ensino presencial para o ensino remoto - e isso não é EaD”. (RODRIGUES, 2021, p. 3, grifos da autora).

Muitos especialistas vão além, ao afirmarem que elas, na realidade, são experiências totalmente diferentes. De fato, enquanto este ERE que temos vivenciado vem acontecendo, basicamente, através de uma espécie de transposição das estratégias didáticas de ensino presenciais à mediação de algumas tecnologias computacionais de Internet, o EaD, por sua vez, já há tempos e de modo estabelecido, tem estruturados: 1) a sua própria concepção político-pedagógica; 2) os seus próprios pressupostos teórico-epistemológicos; e 3) as suas próprias práticas didático-metodológicas.

Acontece que, não obstante tais diferenças estruturais, o ERE traz consigo boa parte das inquietações metodológicas centrais que são inerentes ao EaD: 1) ambos realizam-se efetivamente numa relação interacional mediada pelas TICs e pela constituição de um ensino que depende da composição entre atividades síncronas e assíncronas; 2) ambos pressupõem um nível elevado de autodidatismo por parte dos alunos e, portanto, retiram parte do protagonismo político do professor; 3) ambos põem em dúvida a definição de presença como um critério de aprendizagem, ao provocar a pergunta sobre o conceito divisor de águas "o que significa 'estar presente' numa situação de ensino-aprendizagem?” (MOURA, 2008, p.147).

É necessário, portanto, fazermos uma dupla e (aparentemente) contraditória demarcação conceitual aqui. Por um lado, é fundamental deixar claro que a experiência sob análise neste texto não é de EaD. De modo geral, o que estamos praticando Brasil a fora não deve ser definido como tal. Por outro lado, esta mesma experiência guarda consigo o gérmen do $\mathrm{EaD}$, no sentido de que é justo no pouco em comum que possuem entre si que reside a maior parte do nosso desconforto enquanto professores e professoras.

\section{Frustrações de parte a parte em um processo (atabalhoadamente) inevitável}

Antes de aprofundarmos estes desconfortos inerentes ao nosso ofício, antes de falarmos do que nos é intimamente próprio, é necessário resguardarmos os aspectos problemáticos referentes à forma como fomos literalmente arremessados no ERE.

É provável que todo este cenário emergencial tenha acelerado o que ocorreria cedo ou tarde. A pandemia da COVID-19 acelerou um processo inevitável, qual seja a massificação de práticas de ensino à 
distância. Produziu disruptivamente, e em um só tempo, o que viria a ocorrer paulatinamente, fluindo por entre impositivos culturais, sociais, econômicos e tecnológicos, que se estabeleceriam nos diversos espaços de aprendizagem. O que, de fato, já vinha ocorrendo em todo o mundo, certamente não se constituiria de maneira tão intensiva e uniforme. Afinal, algumas áreas do conhecimento, algumas culturas, algumas gerações vinham acolhendo as práticas de $\mathrm{EaD}$ de maneira mais ou menos receptiva ao longo do tempo.

Numa palavra: o que parecia inevitável tornou-se atabalhoadamente urgente. O fato é que, muito embora a circunstância geral em que estamos não seja propriamente de permitir grandes alegrias, há bem pouca satisfação de parte a parte (entre professores e alunos) com esta situação repentinamente inevitável. Então, este processo abrupto pelo qual todos vem passando tem circunstâncias a serem consideradas.

1) Adoecimento emocional. Embora a própria pandemia já nos adoeça de todas as formas, há fortes indícios de que o ERE aprofundou o adoecimento emocional entre professores e alunos, como mostram algumas pesquisas recentes (SILVA et al., 2020; VIEIRA et al., 2020; OLIVEIRA; SANTOS, 2021).

2) Despreparo metodológico. Alguns levantamentos recentes mostram o quão distantes os docentes universitários estão do uso intensivo de metodologias ativas e de TICs, a não ser como meros coadjuvantes em seus planos de ensino. Além disso, a maioria não se sente segura quanto ao uso de tais instrumentos (LIMA,2016; LEITE et al., 2020; RODRIGUES, 2021).

3) Infraestrutura insuficiente. Tanto para professores como para alunos o acesso a computadores é precário, seja porque ele não atende à necessidade, seja porque é partilhado por outros familiares, ou mesmo não existe este recurso, restando o uso de celulares nem sempre com as condições adequadas também. A qualidade da Internet é igualmente precária para a maioria, assim como o ambiente físico disponível para o estudo dentro das residências. Todas estas (e ainda outras) questões são confirmadas por algumas pesquisas realizadas em função da pandemia (NASCIMENTO et al., 2020; LIMA,2016; LEITE et al., 2020).

Todos os envolvidos foram pegos de surpresa e, nas circunstâncias acima apresentadas, tiveram que se adaptar ao ERE sem qualquer tipo de preparo efetivo. Independente da concepção de ensino que cada um tenha, as frustrações de parte a parte são tão inevitáveis quanto a situação em si.

\section{Alguns aspectos construtivistas do nosso ofício de ensinar}

Estão feitas, portanto, as devidas ressalvas acerca dos graves obstáculos e desafios impostos pelas circunstâncias emergenciais que, ao mesmo tempo em que nos impuseram o ERE (porque era o que tínhamos; era o que dava para ser feito), revelaram o nosso grande distanciamento de uma concepção de ensinoaprendizagem que se baseie, ainda que parcialmente, em EaD. Voltamos, então, à questão que ambos (o ERE e o $\mathrm{EaD}$ ) nos propõem: qual o sentido do ensino?

Em verdade esta pergunta, que vai ao centro do nosso ofício de professor e de professora, deveria ser permanente. E, ao que tudo indica, dadas as nossas atuais circunstâncias, não deve sair da pauta tão cedo. Primeiro, porque dada a imprevisibilidade do andamento da pandemia, é provável que a necessidade do 
distanciamento social perdure. Segundo, porque é improvável que em algum momento no futuro voltemos a praticar exclusivamente a formação educacional presencial.

Então, mesmo quem não chegou a formular aquela pergunta - daquele modo com todas as letras traz consigo a questão, quando, por exemplo, defende a ideia de que só é possível ensinar algo a alguém numa situação de interação presencial e síncrona. Há que se dizer que esta percepção esbarra no que Moura (2008) chamou de "inviabilidade instrucionista", ou seja, uma concepção epistemológica (difícil de sustentar nos dias de hoje) segundo a qual o processo de aprendizagem ocorreria pela recepção de conhecimentos que transitam, através da linguagem, da mente de uma pessoa à mente de outra. Mesmo a ciência natural de base darwinista vem contestando com firmeza esta concepção (HOFFMAN, 2021), que, por sinal, foi desmontada em quase todas as áreas do conhecimento desde os anos sessenta do século passado. Nesta perspectiva de base positivista sensorialista e vericondicionalista, o conhecimento é entendido como uma representação dualista e unívoca de uma realidade pré-existente e composta por objetos independentes do observador. É também uma espécie de produto, um objeto capaz de ser medido e, portanto, administrado. Enfim, o conhecimento seria simplesmente uma espécie de objeto passível de ser transmitido de um a outro indivíduo.

"Conhecimento é tratado como mercadoria que se adquire ('aquisição de conhecimento' continua expressão corriqueira), e que se repassa por meio de processos instrucionistas ostensivos. [...] [Mas,] conhecimento e aprendizagem são atividades humanas que expressam, de maneira exuberante, processos não lineares, além de serem imateriais e dependentes de base material fisiológica. São não lineares tanto em seu processo de formação, e reconstrução, quanto em sua tessitura interna" (DEMO, 2002, p. 123).

Por outro lado, uma concepção de ensino, aprendizagem e conhecimento de base construtivista (ainda que este "guarda-chuvas" conceitual seja tão grande quanto heterogêneo) tende a considerar bem mais viável três pressupostos que o ERE e a EaD têm em comum: 1) o aluno é o protagonista do seu aprendizado que, em essência, é autodidata; 2) o professor estimula, provoca, orienta a aprendizagem do aluno; 3) o aluno é capaz de ser autônomo na organização de sua aprendizagem, mas pode e deve se beneficiar da ação orientadora do professor inerente à sua prática docente.

Ainda que óbvio, é necessário enfatizar que, embora estes pressupostos estejam presentes no EaD, assim como no ERE, a diferença vital é que a estrutura do EaD é totalmente concebida a partir deles. E isso faz toda a diferença, especialmente na atitude dos docentes, que precisam compreendê-los. Como já vimos, no caso do ERE eles são perdidos durante aquela transposição "sala-de-aula-tradicional-para-Internet".

Então, uma estratégia didática construtivista necessariamente atribui ao aprendiz o ato de aprender. Esta forma de conceber o aprendiz tem por trás de si, como vimos, determinados princípios epistemológicos. Mas também possui importantes implicações políticas. Isso porque, como em tal recorte a aprendizagem é sempre e necessariamente autodidata, e isso é uma inerência à nossa própria condição biológica (MATURANA, 1997; MATURANA; VARELA, 2003; HOFFMAN, 2021), ela deixa de ser considerada um processo unilateral e passivo, em que o professor expositor é o centro. O professor que compreende isso, então, precisa necessariamente repensar suas estratégias metodológicas e, mais ainda, reposicionar-se na sua 
relação com os alunos. E esta é uma questão que produz muita ameaça às posições de poder dos professores.

\section{A Estratégia Didática Multissensorial e sua adaptação ao ERE em cursos de graduação da UFPE}

Feita a crítica ao nosso ofício de professor, retomamos o olhar às nossas circunstâncias de COVID19 e de ERE, para afirmar que é possível criarmos estratégias didáticas que ampliem a aprendizagem dos alunos e das alunas, mesmo nas condições limitantes que esta situação de ensino nos impõe. Nesta seção, portanto, são apresentadas as bases da Estratégia Didática Multissensorial e sua aplicação ao ERE, por três semestres letivos, em sete turmas, de três cursos, de dois campi da UFPE, através das plataformas Zoom ${ }^{\circledR} \mathrm{e}$ Google Classroom $^{\circledR}$, com ganhos significativos em relação aos obstáculos e desafios próprios do ERE.

\subsection{As disciplinas, turmas e cursos}

A experiência de ERE em que foi utilizada a Estratégia Didática Multissensorial ocorreu através de um conjunto de seis disciplinas, ministradas durante três semestres letivos, nos cursos de Administração e Engenharias da UFPE do Campus Recife/PE e no curso de Administração do Campus Caruaru/PE (Quadro 1).

Quadro 1 - Disciplinas que compuseram a situação de ensino.

\begin{tabular}{|c|c|c|c|}
\hline \multirow{2}{*}{ Semestre letivo } & Disciplina & Curso & Turmas \\
\hline \multirow{2}{*}{2020.3} & Introdução à Administração & Administração Campus Recife & $1 \mathrm{~N}$ \\
\cline { 2 - 4 } & Comunicação Empresarial & Administração Campus Recife & $2 \mathrm{~A}$ e 2N \\
\cline { 2 - 4 } & Processo Decisório & Administração Campus Caruaru & N6 (c/h parcial) \\
\cline { 2 - 4 } & Administração Estratégica & Administração Campus Caruaru & N8 (c/h parcial) \\
\hline \multirow{2}{*}{2020.1} & Administração & Engenharia Campus Recife & EE \\
\cline { 2 - 4 } & Comunicação Empresarial & Administração Campus Recife & $2 \mathrm{~A}$ \\
\hline
\end{tabular}

Fonte: $\mathrm{O}$ autor.

O semestre letivo 2020.3 foi o primeiro do ERE da UFPE, concebido para funcionar como uma experimentação para professores, professoras, alunas e aluno. Foi ministrado entre agosto e novembro de 2020, com participação facultativa de docentes e discentes. Seu objetivo foi servir como uma prática inicial e experimental de ERE. A ideia era cada docente ministrar uma única disciplina.

Os semestres que se seguiram foram definidos num calendário acadêmico especial, que inseriu três semestres letivos em cada um dos anos 2021 e 2022, de maneira que os semestres suspensos em 2020 fossem recuperados em um intervalo de dois anos. Então, o semestre letivo 2020.1 ocorreu entre janeiro e abril de 2021; e o semestre letivo 2020.2 ocorreu entre maio e setembro de 2021. A alocação da carga horária entre professores e professoras nestes dois semestres foi feita dentro dos procedimentos normais, bem como a participação dos alunos e das alunas. 


\subsection{A Infraestrutura e a Capacitação}

No que diz respeito às TICs, a UFPE fez uma escolha pelo uso das ferramentas que compõem o GSuíte: o Google Classroom para as interações assíncronas e a organização da sala de aula virtual; e o Google Meeting para as interações síncronas utilizando vídeo chamada. Todos os professores e alunos também passaram a ter contas de e-mail institucional do Gmail.

A capacitação consistiu na realização de cursos padrão sobre essas ferramentas. Não houve uma formação aprofundada e generalizada sobre aspectos metodológicos e epistemológicos do ensino e da aprendizagem no contexto dos modelos presenciais e à distância, muito provavelmente porque não havia condições para tal.

Portanto, a preparação dos professores e das professoras para a realização do ERE foi, ela mesma, um processo que se resumiu a demostrar como se transpõe os planos de ensino e as estratégias didáticas tradicionais para um ambiente de interações virtuais. Qualquer ação mais sofisticada neste sentido caberia às iniciativas individuais deste ou daquele professor ou professora.

\subsection{A Estratégia Didática Multissensorial como prática anterior e regular do professor}

Antes de tudo, é preciso ter em mente que mesmo na sala de aula tradicional, nas experiências de ensino "pré-pandêmicas", já havia por parte do professor que ministrou este ERE certo tipo de escolha metodológica, que incluía um nível ampliado de participação dos alunos no seu próprio processo de aprendizagem. Isso se refletia, por exemplo, em um reduzido número de aulas expositivas e de um processo avaliativo baseado na realização de tarefas práticas distribuídas no decorrer do semestre letivo e em substituição às tradicionais provas escritas.

Esta estratégia didática foi construída empiricamente pelo professor e, basicamente, se dá pela inserção dos alunos em uma sequência de momentos multissensoriais de interação com os assuntos, com o professor e com a própria turma. Por multissensorialidade estamos nos referindo a um processo de aprendizagem que combina ações de: 1) visão: leitura individual; 2) escrita: interpretação e produção de resumo das ideias centrais; 3) escuta: apreciação crítica de outras interpretações; 4) escrita coletiva: produção de um texto integrado; 5) exposição oral: apresentação da produção do grupo; 6) escuta qualificada: contato com a versão apresentada pelo professor, tendo tido já todo aquele conjunto de contatos com o assunto, e debate para a eliminação de dúvidas (Quadro 2). 
Quadro 2. A Estratégia Didática Multissensorial.

\begin{tabular}{|c|c|c|c|c|}
\hline Etapa & Disciplina & Local & Participação & Sensorialidade \\
\hline $\begin{array}{l}\text { Momento } \\
\text { Sensorial } 1\end{array}$ & $\begin{array}{l}\text { Leitura individual do texto base do } \\
\text { tema }\end{array}$ & $\begin{array}{c}\text { Extra } \\
\text { sala }\end{array}$ & Individual & Leitura \\
\hline $\begin{array}{c}\text { Momento } \\
\text { Sensorial } 2\end{array}$ & $\begin{array}{l}\text { Produção de paper resumindo } \\
\text { criticamente as ideias centrais do } \\
\text { texto lido }\end{array}$ & $\begin{array}{l}\text { Extra } \\
\text { sala }\end{array}$ & Individual & Compreensão e escrita \\
\hline $\begin{array}{c}\text { Momento } \\
\text { Sensorial } 3\end{array}$ & $\begin{array}{l}\text { Leitura compartilhada dos papers e } \\
\text { debate }\end{array}$ & Sala & Minigrupos & Leitura, análise e debate \\
\hline $\begin{array}{c}\text { Momento } \\
\text { Sensorial } 4\end{array}$ & $\begin{array}{l}\text { Leitura dirigida do texto (o grupo } \\
\text { responde perguntas apresentadas e } \\
\text { estas respostas requerem uma } \\
\text { revisitação a partes do texto } \\
\text { consideradas muito importantes } \\
\text { pelo professor) }\end{array}$ & Sala & Minigrupos & $\begin{array}{l}\text { Releitura e produção } \\
\text { coletiva de respostas e } \\
\text { análises }\end{array}$ \\
\hline $\begin{array}{l}\text { Momento } \\
\text { Sensorial } 5\end{array}$ & $\begin{array}{c}\text { Apresentação das respostas às } \\
\text { perguntas da leitura dirigida, } \\
\text { realizada por cada grupo, e debate } \\
\text { com toda a turma estimulado pelo } \\
\text { professor }\end{array}$ & Sala & Turma & $\begin{array}{c}\text { Apresentação da } \\
\text { produção do grupo e } \\
\text { novo debate }\end{array}$ \\
\hline $\begin{array}{l}\text { Momento } \\
\text { Sensorial } 6\end{array}$ & $\begin{array}{l}\text { Apresentação do tema pelo } \\
\text { professor com participação da turma }\end{array}$ & Sala & Turma & $\begin{array}{l}\text { Escuta da versão do } \\
\text { professor, debate geral, } \\
\text { eliminação de dúvidas }\end{array}$ \\
\hline
\end{tabular}

Fonte: $\mathrm{O}$ autor.

A experiência pessoal de ensino do professor foi construindo este modelo completo, com variações inerentes às especificidades de cada turma. A concepção geral de uma disciplina, na Estratégia Didática Multissensorial, consiste em:

1) o programa: estabelece-se um conjunto de temas ou assuntos integrados que possam ser trabalhados em metade da carga horária;

2) a turma: na primeira aula do semestre são formados grupos de trabalho fixos (GTs), cuja composições são escolhidas pelos alunos;

3) o cronograma: a estratégia deve usar cerca de dois terços da carga horária e cada tema utilizará duas aulas;

4) a preparação: as duas primeiras aulas servem como introdução do tema, explicações sobre a metodologia, montagem dos GTs, introdução aos textos-base, entre outros prolegômenos;

5) a finalização: no último terço da carga horária os GTs apresentam trabalhos de pesquisa ou estudos de caso, com base em todos os temas, sob a orientação do professor;

6) a avaliação: a nota final é a média aritmética de duas notas, sendo a N1 composta pelo somatório de notas obtidas em cada uma das aulas, e a N2 definida pela apresentação do 
trabalho final.

Sendo essa a estrutura geral da disciplina, cada um dos momentos sensoriais tem como finalidade:

1) Momento Sensorial 1: a leitura individual de um texto base do tema é fundamental como experiência de aprendizagem. No entanto, é sabido que com muita frequência o aluno simplesmente vem para a aula sem a leitura prévia.

2) Momento Sensorial 1: a exigência da produção de um paper, além de estimular os alunos a realmente lerem, faz com que pratiquem a compreensão textual e a capacidade de síntese e de análise crítica. Nesta etapa pode ser solicitado também a produção de perguntas que alimentarão o debate em sala.

3) Momento Sensorial 3: a partilha da produção individual em grupo traz vários benefícios, a começar pelo estímulo que também cria na necessidade da leitura do texto. Além disso, a escuta de análises diferentes sobre o mesmo texto amplia o seu entendimento e gera uma dinâmica de aprendizagem em grupo.

4) Momento Sensorial 4: para garantir que os alunos não deixem passar partes cruciais do texto, e novamente para simplesmente colocá-lo em contato com o texto, esta etapa faz com que os alunos precisem fazer um tipo de busca no texto para achar as respostas. Esta atividade de pesquisa é naturalmente criada através de uma leitura totalmente diferente da que foi feita anteriormente.

5) Momento Sensorial 5: nesta etapa os GTs passam a atuar no nível da turma inteira e, na medida em que vão apresentando as suas respostas (que podem ser divididas de várias formas a depender do tempo que se disponha e do tamanho do assunto), o professor estimula o debate com a turma. Este pode ser um momento muito rico de partilha coletiva, além de ser mais um momento de debate.

6) Momento Sensorial 6: por fim, chega o único momento em que o professor vai falar mais do que a turma, apresentando o tema com apoio de toda a sua competência e conhecimento, porém interagindo com alunos que estão introduzidos no tema. A exposição dialogada neste caso ganha uma outra dimensão, sendo tão somente o fechamento do processo de aprendizagem do tema. Geralmente a turma se sente mais estimulada a participar desta exposição porque o próprio professor continua estimulando esse engajamento, que já foi criado desde as etapas anteriores.

Esta é, portanto, a estrutura geral da disciplina concebida a partir da Estratégia Didática Multissensorial. Vale a pena ressaltar que as estratégias didáticas tradicionais, baseadas no pressuposto de que o professor ensina ao expor conteúdos aos alunos, são monossensoriais, na medida em que, mesmo quando estimulam leitura e participação, quase sempre funciona tão somente através de exposições de conteúdo. Numa palavra, nestes casos tudo se resume ao momento sensorial 6. Dá para imaginarmos a "tragédia" que é tal estratégia didática simplesmente transposta aos ambientes de interação remota: alunas e alunos escutando e escutando. 


\subsection{A Estratégia Didática Multissensorial adaptada ao ERE}

Uma vez que a Estratégia Didática Multissensorial está devidamente compreendida, resta saber como ela pode ser praticada remotamente. Embora a natureza metodológica e epistemológica desta concepção seja naturalmente factível à condição estrutural de ensino remoto ou à distância, pela sua natureza não centrada no professor e não baseada em exposição de conteúdo, ainda assim não se pode fazer uma mera transposição. São necessárias adaptações (Quadro 3), sendo uma delas a substituição do Google Meeting pelo Zoom ${ }^{\circledR}$, devido aos recursos muito mais sofisticados desta plataforma, especialmente as Breakouts Rooms, salas específicas que podem ser abertas para alguns dos participantes. O professor cria estas salas muito facilmente e rapidamente distribui os estudantes, podendo ser chamado por eles para ir nestas salas tirar dúvidas. Este recurso viabiliza as atividades em grupo.

Quadro 3. Estratégia Didática Multissensorial adaptada ao ERE.

\begin{tabular}{|c|c|c|c|}
\hline Etapa & Adaptação & Ferramenta & Interação \\
\hline $\begin{array}{l}\text { Momento } \\
\text { Sensorial } 1\end{array}$ & $\begin{array}{l}\text { Os textos compostos por livros e capítulos de obras geralmente } \\
\text { impressas são substituídos por: textos, estudos de caso, vídeos } \\
\text { disponíveis na Internet }\end{array}$ & Google Classroom & Assíncrona \\
\hline $\begin{array}{l}\text { Momento } \\
\text { Sensorial } 2\end{array}$ & Os papers são substituídos por questionários on-line & Google Forms & Assíncrona \\
\hline $\begin{array}{l}\text { Momento } \\
\text { Sensorial } 3\end{array}$ & $\begin{array}{l}\text { Leitura compartilhada das respostas postadas nos questionários } \\
\qquad \text { e debate }\end{array}$ & $\begin{array}{l}\text { Breakouts Rooms no } \\
\text { Zoom }^{\circledR}\end{array}$ & Síncrona \\
\hline $\begin{array}{l}\text { Momento } \\
\text { Sensorial } 4\end{array}$ & $\begin{array}{l}\text { A leitura dirigida do texto é substituída pela criação de uma } \\
\text { apresentação de uma resposta coletiva do grupo, usando } \\
\text { Powerpoint }{ }^{\circledR} \text { ou equivalente }\end{array}$ & $\begin{array}{l}\text { Breakouts Rooms do } \\
\qquad \text { Zoom }^{\circledR}\end{array}$ & Síncrona \\
\hline $\begin{array}{l}\text { Momento } \\
\text { Sensorial } 5\end{array}$ & $\begin{array}{l}\text { Apresentação das respostas às perguntas da leitura dirigida } \\
\text { cede lugar a apresentação da resposta coletiva de cada GT, } \\
\text { combinada com complementos realizados pelo professor }\end{array}$ & $\begin{array}{l}\text { Sala Principal do } \\
\qquad \text { Zoom }^{\circledR}\end{array}$ & Síncrona \\
\hline $\begin{array}{l}\text { Momento } \\
\text { Sensorial } 6\end{array}$ & $\begin{array}{c}\text { Apresentação do tema pelo professor com participação da } \\
\text { turma }\end{array}$ & $\begin{array}{l}\text { Sala Principal do } \\
\text { Zoom }^{\circledR}\end{array}$ & Síncrona \\
\hline
\end{tabular}

Fonte: $\mathrm{O}$ autor.

A adaptação da Estratégia Didática Multissensorial ao ERE, portanto, foi feita desta maneira, o que, naturalmente, gerou aspectos positivos e negativos:

- Aspectos positivos da experiência: 1) a condução das disciplinas fluiu em um ritmo relativamente leve e compassado; 2) a apropriação dos conteúdos foi observada pela qualidade das interações, especialmente no momento sensorial 5; 3) houve raríssima presença de alunos em provas de segunda chamada e final (apenas em uma das turmas, com cinco alunos e alunas); 4) ocorreu intensa participação dos alunos nos momentos dos GTs, como visto nos momentos sensoriais 3 e 4.

- Aspectos negativos da experiência: 1) houve uma queda imensa na participação de aluas e alunos nos momentos sensoriais 5 e $6 ; 2$ ) nestes momentos em que toda a turma está reunida 
numa mesma sala há a permanente sensação de esvaziamento.

Parece que os aspectos negativos são próprios das limitações do ERE e das condições gerais em que todos estamos.

Há que se dizer, a esta altura, que numa situação de $\mathrm{EaD}$ as aulas síncronas ocorreriam, por exemplo, através das chamadas Web Conferences, em que o professor ou a professora vai a um estúdio multimídia equipado e é assessorado por um técnico, enquanto as alunas e os alunos se reúnem numa sala do polo presencial do curso a que estão vinculados e também são assessorados por um tutor. Isso é muito diferente de um professor ou professora que, com o seu computador particular e contando com sua Internet doméstica, faz uma sessão de Meeting com os alunos, que certamente estão apoiados por uma infraestrutura ainda mais amadora e, com frequência, precária.

Mas o nosso caso é de ERE, como já falamos. Então, enquanto os aspectos positivos da experiência sob análise parecem atenuar as dificuldades, os aspectos negativos: 1) surgem em comparação à situação de aula presencial; e 2) também ocorrem na transposição das estratégias didáticas de sala de aula presencial. De tal modo que os benefícios da Estratégia Didática Multissensorial adaptada ao ERE estão demonstrados.

\section{Considerações Finais}

Este artigo teve como objetivo propor o uso de uma estratégia didática, que classificou como (relativamente) construtivista, como um meio de atenuar os diversos obstáculos inerentes a este ERE que temos praticado durante a Pandemia da COVID-19. Ao fazê-lo, evocou uma pergunta crucial para o nosso atual momento como professoras e professores: qual o sentido do ensino no contexto do distanciamento social?

A reflexão crítica estimulada por essa pergunta, se realizada com a devida profundidade, pode levarnos a compreender que, do ponto de vista epistemológico e metodológico, há algo mais essencial a ser (re)pensado e que reescreve assim: qual o sentido do ensino em qualquer contexto?

Esta é, de fato, a questão permanentemente crucial. Ocorre que, com frequência, ela se depara com uma concepção de aprendizagem que, embora consagrada pelo senso comum, não se sustenta epistemologicamente já há muitas décadas. Mas não se trata apenas de ignorância. Estamos falando da manutenção de posições de poder, de tal modo consagradas e repetidas há séculos, que se cristalizam na própria identidade do ofício de ensinar. A ponto de aquela pergunta sequer fazer sentido para muitos professores e professoras: “Como assim 'qual o sentido?'. O sentido é de mão única: eu ensino e os alunos aprendem".

Entretanto, qualquer que seja a situação de presença (longe ou perto; síncrona ou assíncrona; dentro ou fora de sala de aula; com ou sem o uso de TICs), essa concepção é igualmente superficial, mesmo nas salas de aula tradicionais. De tal modo que, embora estejamos falando de ERE, no fundo estamos tratando do que fazemos quando nos colocamos nesta posição de professor. Em que consiste assumir esta relação? Como eu posso ajudar os estudantes a aprenderem?

Como o leitor e a leitora já estão cientes, a pretensão final deste artigo não é, verdadeiramente, propor um método de ensino - a aqui chamada Estratégia Didática Multissensorial. Até porque não há nada de novo nisto. A ideia de analisar um instrumento metodológico numa experiência de ERE serve ao propósito de 
contemplar a relação de ensino-aprendizagem sob perspectivas epistemológicas e políticas que diminuam a centralidade no professor de um papel de expositor e transmissor de conhecimentos. Nesta outra perspectiva, embora continuem existindo as referências de conteúdo programático da disciplina ministrada e o argumento de autoridade de quem ocupa a posição de professor, as questões passam menos pela adequação dos discursos dos alunos aos dos professores, e mais por uma possibilidade de uma dialogia entre profissionais que (também) aprendem juntos.

Se o leitor e a leitora deste artigo forem típicos pesquisadores e pesquisadoras brasileiros e forem professores e professoras de Instituições de Ensino Superior, este artigo encontrou seu endereço certo.

\section{Agradecimentos}

$\mathrm{O}$ autor gostaria de agradecer à FACEPE e ao CNPq pelo seu apoio financeiro (ref. APQ-0887-6.02/14) durante a realização deste trabalho.

\section{Referências}

DEMO, Pedro. Complexidade e aprendizagem: a dinâmica não linear do conhecimento. São Paulo: Atlas, 2002.

HOFFMAN, Donald. Vemos a realidade como ela é? TED. Disponível em: <https://www.ted.com/talks/donald_hoffman_do_we_see_reality_as_it_is/transcript?language=pt-br>. Acesso em: 02 set. 2021.

LEITE, Nahara M. LIMA, Elidiene G. O. de; CARVALHO, Ana Beatriz G. Os Professores E O Uso De Tecnologias Digitais Nas Aulas Remotas Emergenciais, No Contexto da Pandemia da COVID-19 Em Pernambuco. Em Teia: Revista de Educação Matemática e Tecnológica Iberoamericana - vol. 11 número $2-2020$.

LIMA. Renato A. de. A utilização das TICs na formação inicial de professores do curso de químicalicenciatura do CAA/UFPE. Trabalho de Conclusão de Curso. Disponível em: <https://repositorio.ufpe.br/bitstream/123456789/39573/1/LIMA\%2c\%20Renato\%20Alves\%20de.pdf>. 2016.

MATURANA, Humberto R. O que é ver?. In: MAGRO, Cristina; GRACIANO, Miriam; VAZ, Nelson. (org.). A Ontologia da Realidade. Belo Horizonte: UFMG, 1997.

MATURANA, Humberto R.; VARELA, Francisco J. G. A árvore do conhecimento: as bases biológicas da compreensão humana. São Paulo: Palas Athena, 2003.

MOURA, Guilherme L. Todo Ensino é a Distância! Reflexões sobre a Inviabilidade Instrucionista da Presença numa Experiência de EAD. REGES: Revista Eletrônica de Gestão, v. 1, p. 147-155, 2008.

NASCIMENTO, Paulo M.; RAMOS, Daniela L.; MELO, Adriana A. S. de; CASTIONI, Remi. Acesso domiciliar à Internet e ensino remoto durante a pandemia. Nota Técnica N.88 - IPEA/DISOC-Diretoria de Estudos e Políticas Sociais. Agosto/2020.

OLIVEIRA, Erik C. de.; SANTOS, Vera M. dos. Adoecimento mental docente em tempos de pandemia. Brazilian Journal of Development, Curitiba, v.7, n.4, p.39193-39199, apr 2021.

ROCHA, Roberta. Profissionais explicam a diferença entre ensino a distância e ensino remoto. Disponível em: <https://www2.ifal.edu.br/noticias/profissionais-explicam-a-diferenca-entre-ensino-remoto-e-ensino-adistancia>. Acesso em: 02 set. 2021.

RODRIGUES, Elisa. Ensino remoto na Educação Superior: desafios e conquistas em tempos de pandemia. Disponível em: <https://horizontes.sbc.org.br/index.php/2020/06/ensino-remoto-na-educacao-superior/>. Acesso em: 09 set. 2021. 
SENADO FEDERAL. Universidade: doutores que não chegam às empresas e à pesquisa na indústria do Brasil. Disponível em: <https://www.senado.gov.br/noticias/Jornal/emdiscussao/inovacao/universidadedoutores-empresas-pesquisa-na-industria-do-brasil.aspx>. Acesso em: 02 set. 2021.

SCHULZ, Peter. Para quem os cientistas escrevemos?, Disponível em:

<https://www.unicamp.br/unicamp/ju/artigos/peter-schulz/para-quem-os-cientistas-escrevemos>. Acesso em: 03 set. 2021.

SILVA, Andrey F. da; Estrela, Fernanda M.; LIMA, Nayara S.; ABREU, Carlos T. de A. | Saúde mental de docentes universitários em tempos de pandemia. Physis: Revista de Saúde Coletiva, Rio de Janeiro, v. 30(2), e300216, 2020.

VIEIRA, K. M. et al. Vida de Estudante Durante a Pandemia: Isolamento Social, Ensino Remoto e Satisfação com a Vida. EaD em Foco, v. 10, n. 3, e1147, 2020. 